\title{
Prevalence of blood type A and risk of vascular complications following transcatheter aortic valve implantation
}

\author{
M.-T. Rofe ${ }^{1}$-Y. Shacham ${ }^{1}$ A. Steinvi ${ }^{1}$ L. Barak $^{1} \cdot$ M. Hareuveni ${ }^{2} \cdot$ S. Banai ${ }^{1}$ \\ G. Keren $^{1} \cdot$ A. Finkelstein ${ }^{1} \cdot$ H. Shmilovich ${ }^{1}$
}

Published online: 9 February 2016

(C) The Author(s) 2016. This article is published with open access at Springerlink.com

\begin{abstract}
Objectives To assess the prevalence of blood type A among patients referred for transcatheter aortic valve implantation (TAVI) and whether it is related to vascular complications. Backgrounds Vascular complications following TAVI are associated with adverse outcomes. Various blood types, particularly type A, have been shown to be more prevalent in cardiovascular diseases and to be related to prognosis.

Methods The prevalence of various blood types in a cohort of 491 consecutive patients who underwent TAVI was compared with a control group of 6500 consecutive hospitalised patients. The prevalence and predictors of vascular complications and bleeding events were evaluated in the blood type A group and were compared with non-type A patients.

Results The mean age of TAVI patients was $83 \pm 6$ years, and $40 \%$ were males. Patients were divided into two groups: blood type $\mathrm{A}(n=220)$ and non-type $\mathrm{A}(n=271)$. Type A was significantly more prevalent in the TAVI group than in the control group ( 45 vs. $38 \%, p=0.023$ ). Compared with the non-type A group, patients with blood type A had more major and fatal bleeding ( 14.5 vs. $8.1 \%, p=0.027)$ and more vascular complications (any vascular complication: 24.5 vs. $15.9 \% p=0.016$; major vascular complications: 12.3
\end{abstract}

M.-T. Rofe and Y. Shacham authors contributed equally

H. Shmilovich

haim.shmilovich@gmail.com

1 Department of Cardiology, Tel Aviv Sourasky Medical Center, Affiliated to the Sackler Faculty of Medicine, Tel Aviv, Israel

2 Department of Haematology, Tel Aviv Sourasky Medical Center, Tel Aviv, Israel vs. $7 \% p=0.047$ ). In a multivariable analysis, blood type A emerged as a significant and independent predictor for vascular complications and bleeding events.

Conclusions Blood type A is significantly more prevalent in TAVI patients than in the general population and is related to higher rates of vascular and bleeding complications.

Keywords Transcatheter aortic valve implantation .

Aortic stenosis · Blood type A - Vascular complications

\section{Introduction}

Severe aortic stenosis is a major cause of morbidity and mortality in the elderly [1]. The risk of surgical aortic valve replacement rises dramatically in relation to comorbidities which can be evaluated using the Euroscore system [2, 3] thus deferring a large group of patients from surgery. In the last decade, transcatheter aortic valve implantation (TAVI) was shown to confer a lower risk of morbidity and mortality in this subset of patients with a high surgical risk and has now become common practice [4-6], but vascular complications after TAVI are associated with adverse short- and long-term outcomes [6-8].

Recent studies have confirmed that the $\mathrm{ABO}$ locus that encodes for the $\mathrm{ABO}$ blood type may be associated with myocardial infarction [9] and venous thromboembolism $[10,11]$. Non-O blood types, mostly type A, were related to increased prevalence of morbidity and mortality in various cardiovascular diseases [12-14] but this was not studied in patients undergoing TAVI.

We investigated the prevalence of blood type A in TAVI patients vs. its prevalence in the general population and whether it is related to periprocedural vascular complications as compared with non-type A patients who underwent TAVI. 


\section{Methods}

\section{Study population}

The data for the present study were collected between the years 2009 and 2014 at a single tertiary-care facility [15]. The study was approved by the institutional ethics committee and written informed consent was obtained from each patient. Patients were recruited during their participation in the Tel-Aviv Angiography Prospective Study [16]. The diagnosis of severe symptomatic aortic stenosis was based on clinical, echocardiographic and haemodynamic criteria [17]. Suitability and eligibility for TAVI were determined by a joint team consisting of an interventional cardiologist, a cardiac surgeon, and an echocardiographer. The control group representing the general population consisted of 6500 consecutive patients who were hospitalised and underwent blood type sampling for other clinical reasons.

\section{TAVI procedure}

Two types of aortic valve prostheses were implanted: The CoreValve prosthesis (Medtronic, Minneapolis, MN, USA) and the Edwards Sapien or Sapien XT prosthesis (Edwards Lifesciences, Irvine, California). For all TAVI procedures, three senior interventional cardiologists performed the peripheral aspects of the TAVI procedures (introduction of the sheaths through the femoral artery, Prostar closure device deployment, and the suturing of the entry ports). Valve type and size were planned prior to the procedure according to preprocedural clinical, echocardiographic, angiographic and $\mathrm{CT}$ parameters and at the discretion of the senior interventional cardiologist. The available valve sizes for the Edwards Sapien XT prosthesis were 23 and $26 \mathrm{~mm}$ and the valve sizes for the CoreValve prosthesis were 26 , 29 , and $31 \mathrm{~mm}[15]$.

\section{Definition of vascular complications}

The original consensus report of the Valve Academic Research Consortium (VARC-1) standardised the endpoint definitions of TAVI procedures including the occurrence of vascular complications [18]. During 2012, these endpoints were updated - known as VARC-2 [19]. While the general definitions of vascular complications were unchanged following the update, VARC-2 incorporated a more rigorous approach to bleeding and haemoglobin decline following TAVI, stating that major bleeding definitions (a haemoglobin drop $>3 \mathrm{~g} / \mathrm{dl}$ or transfusion of two or more packed red blood cell units) should also be considered to be major vascular complications, while in the former VARC-1 endpoints, only transfusion of $\geq 4$ packed red blood cell units was considered a major vascular complication. Importantly, in both consensus documents, interventional or surgical repair for failed percutaneous closure during the initial procedure without other clinical consequences was considered a minor vascular complication [18, 19]. Accordingly, we classified vascular complications using VARC-2.

\section{Statistical analysis}

All data are displayed as mean ( \pm standard deviation) for continuous variables, and as the number (percentage) of patients in each group for categorical variables. The Student's t-test and $\chi^{2}$ test were used to evaluate the statistical significance of differences between continuous and categorical variables, respectively.

Logistic regression models used any vascular complications, or the combined outcome variable of any vascular complication or major bleeding, as the dependant variables, and they were adjusted to age, gender, body mass index (BMI), diabetes mellitus, hypertension, estimated glomerular filtration rate, previous stroke, previous cardiac surgery, Society of Thoracic Surgeons risk model (STS) score, ejection fraction and anaemia. Cox proportional hazard models for all-cause mortality were adjusted separately for major vascular complications as well as to other predictors of mortality following TAVI $[5,20]$ : gender, age, BMI, systolic heart failure, prior coronary artery bypass graft, prior percutaneous coronary intervention, atrial fibrillation, pulmonary disease, STS score, preoperative mean gradient, and creatinine clearance test. Analyses were considered significant at a two-tailed $\mathrm{p}$ value of less than 0.05. SPSS statistical package was used to perform statistical evaluation (SPSS, Chicago, IL).

\section{Results}

The study population who underwent TAVI included 491 patients with a mean age of $83 \pm 6$ years (range 61-98), of whom 196 (40\%) were males. When comparing differences in blood type between TAVI patients and 6500 consecutive (non-TAVI) hospitalised patients, type A was significantly more prevalent in the TAVI group than in the above-mentioned control group ( 45 vs. $38 \%, p=0.023$ ). All other blood types were distributed evenly between the TAVI and the control group.

We then divided our patients into two groups according to blood type: type A $(n=220)$ and non-type A $(n=271)$. Baseline demographic, clinical, and procedural characteristics for the two groups are presented in Table 1.

The 30-day adverse events in the type A vs. the non-type A groups are presented in Table 2. Major and fatal bleeding were more prevalent in the type A group (14.5 vs. $8.2 \%$, $p=0.027)$. The rate of vascular complications was higher 
Table 1 Baseline study population characteristics

\begin{tabular}{|c|c|c|c|}
\hline Units & $\begin{array}{l}\text { Blood type A } \\
(n=220)\end{array}$ & $\begin{array}{l}\text { Non-type A } \\
(n=271)\end{array}$ & $p$ value \\
\hline $\begin{array}{l}\text { Age, years }(\text { mean } \pm S D) \\
\text { years }\end{array}$ & $83 \pm 6$ & $83 \pm 6$ & 0.748 \\
\hline Male gender & $86,40 \%$ & $127,47 \%$ & 0.084 \\
\hline Diabetes mellitus & $65,29 \%$ & $110,40 \%$ & 0.011 \\
\hline Dyslipidaemia & $172,78 \%$ & $221,81 \%$ & 0.353 \\
\hline Hypertension & $191,87 \%$ & $238,88 \%$ & 0.739 \\
\hline Smoking history & $50,23 \%$ & $86,32 \%$ & 0.027 \\
\hline $\mathrm{BMI}($ mean $\pm \mathrm{SD}) \mathrm{kg} / \mathrm{m}^{2}$ & $27 \pm 5$ & $28 \pm 5$ & 0.110 \\
\hline $\mathrm{CCT}($ mean $\pm \mathrm{SD}) \mathrm{ml} / \mathrm{min}$ & $63 \pm 18$ & $62 \pm 20$ & 0.770 \\
\hline PVD & $10,4.5 \%$ & $23,8.5 \%$ & 0.083 \\
\hline Stroke & $21,9.5 \%$ & $30,11.1 \%$ & 0.582 \\
\hline Systolic heart failure & $36,16 \%$ & $47,17 \%$ & 0.773 \\
\hline History of CAD & $135,61 \%$ & $163,60 \%$ & 0.784 \\
\hline Prior MI & $32,14.5 \%$ & $56,21 \%$ & 0.079 \\
\hline Prior $\mathrm{CABG}$ & $39,19 \%$ & $53,20 \%$ & 0.605 \\
\hline Permanent pacemaker & $16,7.3 \%$ & $40,14.8 \%$ & 0.009 \\
\hline AF (any type) & $59,27 \%$ & $88,32 \%$ & 0.174 \\
\hline $\mathrm{EF} \%($ mean $\pm \mathrm{SD})$ & $56 \pm 7.3$ & $55 \pm 7.7$ & 0.253 \\
\hline STS score $($ mean \pm SD) & $4.2 \pm 2.5$ & $4.3 \pm 3$ & 0.510 \\
\hline Euroscore (mean $\pm \mathrm{SD})$ & $25 \pm 14$ & $23 \pm 14$ & 0.259 \\
\hline $\operatorname{AVA}($ mean $\pm \mathrm{SD}) \mathrm{cm}^{2}$ & $0.721 \pm 0.19$ & $0.714 \pm 0.18$ & 0.685 \\
\hline Dialysis & $4,2 \%$ & $6,2 \%$ & 0.757 \\
\hline Frailty & $36,17 \%$ & $33,12 \%$ & 0.164 \\
\hline PCI pre TAVI & 117 & 141 & 0.800 \\
\hline \multicolumn{4}{|l|}{ Medications post TAVI } \\
\hline ASA & 193 & 226 & 0.178 \\
\hline ADP & 179 & 226 & 0.557 \\
\hline $\mathrm{AC}$ & 45 & 58 & 0.798 \\
\hline $\mathrm{ASA}+\mathrm{ADP}$ & 164 & 188 & 0.207 \\
\hline$(\mathrm{ASA}$ or $\mathrm{ADP})+\mathrm{AC}$ & 20 & 29 & 0.555 \\
\hline $\mathrm{ASA}+\mathrm{ADP}+\mathrm{AC}$ & 23 & 24 & 0.550 \\
\hline Only AC & 2 & 5 & 0.385 \\
\hline
\end{tabular}

$A C$ anticoagulation, $A D P$ adenosine diphosphate inhibitors, $A F$ atrial fibrillation, $A S A$ aspirin, $A V A$ aortic valve area, $B M I$ body mass index, $C A B G$ coronary artery bypass grafting, $C A D$ coronary artery disease, $C A F$ chronic atrial fibrillation, $C C T$ creatinine clearance test, $C O P D$ chronic obstructive pulmonary disease, $E F$ ejection fraction, $M I$ myocardial infarction, $P C I$ percutaneous coronary intervention, $P V D$ peripheral vascular disease, $S D$ standard deviation, STS Society of Thoracic Surgeons risk model, TAVI transcatheter aortic valve implantation

in the type A group including both major (12.3 vs. 7\%, $p=0.047$ ), as well as major or minor vascular complications $(24.5$ vs. $15.9 \%, p=0.016)$. There was no difference in 30-day, 1-year, and all-time mortality.

In multivariable linear regression analysis, blood type A was significantly and independently associated with vascular complications (OR 1.64, 95\% CI 1.04-2.67, $p=0.033$ ) and was marginally associated with vascular complications or major bleeding (OR 1.57, 95\% CI 0.99-2.2167, $p=0.056$ ) (Table 3).
Table 2 Thirty-day adverse events

\begin{tabular}{|c|c|c|c|}
\hline Events/Patient numbers & $\begin{array}{l}\text { Blood type } \\
\text { A }(n=220)\end{array}$ & $\begin{array}{l}\text { Non-type } \\
\text { A }(n=271)\end{array}$ & $p$ value \\
\hline MI & 0 & 0 & NA \\
\hline Cardiogenic shock & $4(1.8 \%)$ & $6(2.2 \%)$ & 0.757 \\
\hline Respiratory failure & $12(5.5 \%)$ & $17(6.3 \%)$ & 0.702 \\
\hline Ventricular tachycardia & 0 & 0 & NA \\
\hline Ventricular fibrillation & $1(0.5 \%)$ & 0 & 0.267 \\
\hline New atrial fibrillation & $13(5.9 \%)$ & $17(6.3 \%)$ & 0.867 \\
\hline Conduction defect & $73(33.2 \%)$ & $97(35.8 \%)$ & 0.545 \\
\hline Stroke & $2(0.9 \%)$ & $5(1.8 \%)$ & 0.384 \\
\hline New pacemaker & $40(18.2 \%)$ & $60(22.1 \%)$ & 0.279 \\
\hline Bleeding- major/fatal & $32(14.5 \%)$ & $22(8.1 \%)$ & 0.024 \\
\hline AKI during hospitalisation & $33(15 \%)$ & $51(18.8 \%)$ & 0.264 \\
\hline VC-minor & $27(12.3 \%)$ & $24(8.9 \%)$ & 0.218 \\
\hline VC-major & $27(12.3 \%)$ & $19(7 \%)$ & 0.047 \\
\hline VC-minor or major & $54(24.5 \%)$ & $43(15.9 \%)$ & 0.016 \\
\hline Surgery for VC & $7(3.2 \%)$ & $4(1.5 \%)$ & 0.204 \\
\hline Use of packed cells ( 1 or more) & $81(36.8 \%)$ & $86(31.7 \%)$ & 0.237 \\
\hline Sepsis & $6(2.7 \%)$ & $5(1.8 \%)$ & 0.511 \\
\hline Conversion to open surgery & $1(0.5 \%)$ & $1(0.4 \%)$ & 0.882 \\
\hline Unplanned CPB during TAVI & 0 & 0 & NA \\
\hline Coronary obstruction & $1(0.5 \%)$ & $1(0.4 \%)$ & 0.882 \\
\hline Ventricular septal perforation & 0 & 0 & NA \\
\hline Mitral valve damage & $1(0.5 \%)$ & $1(0.4 \%)$ & 0.882 \\
\hline Tamponade & $3(1.4 \%)$ & $1(0.4 \%)$ & 0.223 \\
\hline Endocarditis & 0 & 0 & NA \\
\hline Valve thrombosis & 0 & 0 & NA \\
\hline Valve migration & 0 & $2(0.7 \%)$ & 0.202 \\
\hline Valve embolisation & $1(0.5 \%)$ & $5(1.8 \%)$ & 0.163 \\
\hline TAVI-in-TAVI & 0 & $4(1.5 \%)$ & 0.07 \\
\hline 30 day mortality & $8(3.6 \%)$ & $6(2.2 \%)$ & 0.346 \\
\hline
\end{tabular}

\section{Discussion}

In the present study we demonstrated that among patients undergoing TAVI, blood type A was significantly more prevalent as compared with the general population, and that type A was independently and significantly associated with vascular complications.

Since 1901, when Landsteiner identified the ABO blood type system and its importance in transfusion and transplantation medicine, there has been debate regarding its usefulness as a predictor of diseases, in particular cardiovascular diseases. Carpeggiani et al. showed that non-O blood types are a predictor of increased mortality in patients with ischaemic heart disease and that it increases the risk of cardiac death amongst non-elderly patients [21]. In 1969, Jick et al. reported a deficit of patients with blood type $\mathrm{O}$ among those who received anticoagulants for venous thromboembolism [22]. A number of later studies elucidated that ABO blood types, particularly non-O blood types, are associated with 
Table 3 Logistic regression models

\begin{tabular}{|c|c|c|c|c|c|c|}
\hline \multirow[t]{2}{*}{ Correlates: } & \multicolumn{3}{|c|}{ Model 1 ${ }^{\mathrm{a}}$} & \multicolumn{3}{|c|}{ Model $2^{b}$} \\
\hline & $p$ & OR & $95 \% \mathrm{CI}$ & $p$ & OR & $95 \% \mathrm{CI}$ \\
\hline Age & 0.701 & 0.991 & $0.946-1.038$ & 0.849 & 0.996 & $0.951-1.042$ \\
\hline Gender & 0.192 & 1.397 & $0.845-2.311$ & 0.141 & 1.476 & $0.879-2.479$ \\
\hline $\mathrm{DM}$ & 0.058 & 0.597 & $0.350-1.018$ & 0.017 & 0.521 & $0.305-0.890$ \\
\hline Hypertension & 0.198 & 1.694 & $0.760-3.777$ & 0.510 & 1.287 & $0.607-2.726$ \\
\hline $\mathrm{eGFR}^{\mathrm{c}}$ & 0.830 & 0.999 & $0.985-1.012$ & 0.331 & 1.007 & $0.993-1.021$ \\
\hline STS score & 0.183 & 1.070 & $0.968-1.183$ & 0.036 & 1.117 & $1.008-1.239$ \\
\hline Prior stroke & 0.227 & 1.560 & $0.759-3.205$ & 0.342 & 1.421 & $0.688-2.934$ \\
\hline LVEF \% & 0.351 & 1.016 & $0.982-1.052$ & 0.156 & 1.026 & $0.990-1.062$ \\
\hline Blood type A & 0.033 & 1.670 & $1.043-2.674$ & 0.056 & 1.576 & $0.989-2.510$ \\
\hline Anaemia & 0.702 & 1.103 & $0.666-1.827$ & 0.821 & 0.926 & $0.477-1.799$ \\
\hline
\end{tabular}

$C I$ confidence interval, $D M$ diabetes mellitus, $L V E F$ left ventricular ejection fraction, $e G F R$ estimated glomerular filtration rate, $O R$ odds ratio, STS Society of Thoracic Surgeons risk model

${ }^{a}$ Model 1: dependant variable: Any vascular complication

${ }^{b}$ Model 2: dependant variable: Any vascular complication or major bleeding

ceGFR in $\mathrm{ml} / \mathrm{min} / 1.73 \mathrm{~m}^{2}$

major cardiovascular risk factors and/or increased rate of cardiovascular events [23, 24]. However, there is limited consensus regarding the magnitude and significance of the $\mathrm{ABO}$ effects at the population level and whether it relates to all disorders equally or predominantly modulates thrombotic pathways and disorders [25]. In addition, a genomewide study showed an association between ABO blood types and myocardial infarction in the presence of coronary artery atherosclerosis [9]. Other reports, however, found no difference in the incidence of ABO blood type when patients with congenital and rheumatic valvular heart disease were compared with a control group [26]. Recently, various studies pointed to the association between blood type $A$ and vascular diseases. One of them, a meta-analysis published by He et al., on 90,000 participants and more than 2 million person-years, showed that non-O blood types had a higher risk of coronary heart disease compared with blood type $\mathrm{O}$ [27].

Several mechanisms have been proposed to explain the possible relationship between blood types and vascular complications. ABO antigens are known to be carried by several platelet glycoproteins (GPs), for example, GPIb, GPIIb, GPIIIa, and platelet endothelial cell adhesion molecule (PECAM) [28], which play important roles in platelet function. GPIIb is an integral component of the GPIIb-GPIIIa fibrinogen receptor complex, which represents the critical final common pathway for platelet-driven thrombosis in homeostasis and pathological arterial thrombosis including acute myocardial infarction. Genetic variation in GPIIb that modulates fibrinogen binding has been associated with altered risk of thrombosis and myocardial infarction [29], so it is conceivable that ABO-driven carbohydrate modification of GPIIb might alter its functional interactions with fibrinogen and thus platelet-mediated thrombosis. However, this hypothesis has not been adequately addressed to date.
Besides GPIIb and PECAM, blood type A antigen is also expressed on other uncharacterised platelet proteins. Thus these and other uncharacterised $\mathrm{ABO}$-expressing platelet proteins may also act as potential functional modulators of the $\mathrm{ABO}$ associations with arterial thrombosis and cardiovascular events.

Previous data demonstrated that relative to non-type $\mathrm{O}$, carriers of type $\mathrm{O}$ have significantly lower circulating plasma Von Willebrand factor (VWF) and factor VIII (FVIII) levels [30]. Although this clinically important effect of ABO type on plasma VWF-FVIII levels is well established, the mechanism through which it is mediated is not completely resolved. ABO appears to have direct functional effects on circulating VWF and indirectly (via influence of VWF levels) modulates FVIII levels. Whether VWF in platelets (a relatively abundant source) undergoes any modification by $\mathrm{ABO}$ remains controversial; such modification could alter platelet production and subsequent turnover of VWF, particularly locally during platelet-driven arterial thrombosis, although this remains to be established.

The limitation of this study is its relatively medium-sized study sample, a one-centre experience and the retrospective nature of the analyses. Further studies will elucidate the important questions as to whether patients with mild aortic stenosis and blood type A progress more rapidly to severe symptomatic aortic stenosis and the need for intervention and thus for a more rigorous follow-up, and whether patients with blood type A undergoing TAVI need a longer and more careful follow-up for vascular complications.

In conclusion, in this study we showed for the first time that patients referred for TAVI due to severe aortic stenosis have a higher prevalence of blood type A. We also showed that blood type A confers a higher risk of vascular complications, independent of other confounders. Future larger and multi-centre studies will assess whether blood type $\mathrm{A}$ is 
related to other aspects of diagnosis and prognosis in cardiovascular diseases and procedures.

Conflicts of interest None declared.

\section{Funding None.}

Open Access This article is distributed under the terms of the Creative Commons Attribution 4.0 International License (http://creativecommons.org/licenses/by/4.0/), which permits unrestricted use, distribution, and reproduction in any medium, provided you give appropriate credit to the original author(s) and the source, provide a link to the Creative Commons license, and indicate if changes were made.

\section{References}

1. Osnabrugge RL, Mylotte D, Head SJ, et al. Aortic stenosis in the elderly: disease prevalence and number of candidates for transcatheter aortic valve replacement: a meta-analysis and modeling study. J Am Coll Cardiol. 2013;62:1002-12.

2. Roques F, Michel P, Goldstone AR, et al. The logistic EuroSCORE. Eur Heart J. 2003;24:881-2.

3. Roques F, Nashef SA, Michel P, et al. Risk factors and outcome in European cardiac surgery: analysis of the EuroSCORE multinational database of 19030 patients. Eur J Cardiothorac Surg. 1999;15:816-22, discussion 22-3.

4. Makkar RR, Fontana GP, Jilaihawi H, et al. Transcatheter aorticvalve replacement for inoperable severe aortic stenosis. N Engl J Med. 2012;366:1696-704.

5. Kodali SK, Williams MR, Smith CR, et al. Two-year outcomes after transcatheter or surgical aortic-valve replacement. N Engl J Med. 2012;366:1686-95.

6. Leon MB, Smith CR, Mack M, et al. Transcatheter aortic-valve implantation for aortic stenosis in patients who cannot undergo surgery. N Engl J Med. 2010;363:1597-607.

7. Smith CR, Leon MB, Mack MJ, et al. Transcatheter versus surgical aortic-valve replacement in high-risk patients. N Engl J Med. 2011;364:2187-98.

8. Stepinska J, Czerwinska K, Witkowski A, et al. Risk factors for bleeding complications in patients undergoing transcatheter aortic valve implantation (TAVI). Cardiol J. 2013;20:125-33.

9. Reilly MP, Li M, He J, et al. Identification of ADAMTS7 as a novel locus for coronary atherosclerosis and association of $\mathrm{ABO}$ with myocardial infarction in the presence of coronary atherosclerosis: two genome-wide association studies. Lancet. 2011;377:383-92.

10.Heit JA, Armasu SM, Asmann YW, et al. A genome-wide association study of venous thromboembolism identifies risk variants in chromosomes 1q24.2 and 9q. J Thromb Haemost. 2012;10:1521-31.

11. Terraube V, O'Donnell JS, Jenkins PV. Factor VIII and von Willebrand factor interaction: biological, clinical and therapeutic importance. Haemophilia. 2010;16:3-13.

12. Medalie JH, Levene C, Papier C, et al. Blood groups, myocardial infarction and angina pectoris among 10,000 adult males. N Engl J Med. 1971;285:1348-53.

13. Cronenwett JL, Davis JT Jr, Garrett HE. ABO blood group and serum lipids in female atherosclerosis. J Cardiovasc Surg (Torino). 1983;24:658-61.
14. Anvari MS, Boroumand MA, Shoar S, et al. Ascending aorta aneurysm and blood group A among Iranian patients. Thromb Res. 2013;131:e51-3.

15. Finkelstein A, Birati EY, Abramowitz Y, et al. Transcatheter aortic valve implantation: a single-center experience of 300 cases. Isr Med Assoc J. 2013;15:613-6.

16. Steinvil A, Sadeh B, Arbel Y, et al. Prevalence and predictors of concomitant carotid and coronary artery atherosclerotic disease. J Am Coll Cardiol. 2011;57:779-83.

17. Bonow RO, Carabello BA, Chatterjee K, et al. ACC/AHA 2006 Guidelines for the management of patients with valvular heart disease. Circulation. 2006;114:e84-231.

18. Leon MB, Piazza N, Nikolsky E, et al. Standardized endpoint definitions for transcatheter aortic valve implantation clinical trials: a consensus report from the Valve Academic Research Consortium. Eur Heart J. 2011;32:205-17.

19. Kappetein AP, Head SJ, Genereux P, et al. Updated standardized endpoint definitions for transcatheter aortic valve implantation: the valve academic research consortium-2 consensus document. J Am Coll Cardiol. 2012;60:1438-54.

20. Rodes-Cabau J, Webb JG, Cheung A, et al. Long-term outcomes after transcatheter aortic valve implantation: insights on prognostic factors and valve durability from the Canadian multicenter experience. J Am Coll Cardiol. 2012;60:1864-75.

21. Carpeggiani C, Coceani M, Landi P, et al. ABO blood group alleles: a risk factor for coronary artery disease. An angiographic study. Atherosclerosis. 2010;211:461-6.

22. Jick H, Slone D, Westerholm B, et al. Venous thromboembolic disease and ABO blood type. A cooperative study. Lancet. 1969;1:539-42.

23. Medalie JH, Levene C, Papier C, et al. Blood groups, myocardial infarction and angina pectoris among 10,000 adult males. N Engl J Med. 1971,285:1348-53.

24. Ketch TR, Turner SJ, Sacrinty MT, et al. ABO blood types: influence on infarct size, procedural characteristics and prognosis. Thromb Res. 2008;123:200-5.

25. Oriol R, Mollicone R, Coullin P, et al. Genetic regulation of the expression of $\mathrm{ABH}$ and Lewis antigens in tissues. APMIS Suppl. 1992;27:28-38.

26. Sartor V, Fraser RS. Abo blood groups in patients with congenital and rheumatic valvular heart disease. Can Med Assoc J. 1964;90:428-9.

27. He M, Wolpin B, Rexrode K, et al. ABO blood group and risk of coronary heart disease in two prospective cohort studies. Arterioscler Thromb Vasc Biol. 2012;32:2314-20.

28. Hou M, Stockelberg D, Rydberg L, et al. Blood group A antigen expression in platelets is prominently associated with glycoprotein $\mathrm{Ib}$ and IIb. Evidence for an A1/A2 difference. Transfus Med. 1996;6:51-9,

29. Cadroy Y, Sakariassen KS, Charlet JP, et al. Role of 4 platelet membrane glycoprotein polymorphisms on experimental arterial thrombus formation in men. Blood. 2001;98:3159-61.

30. Tirado I, Mateo J, Soria JM, et al. The ABO blood group genotype and factor VIII levels as independent risk factors for venous thromboembolism. Thromb Haemost. 2005;93:468-74. 